\title{
О ЛЕКСИКО-СЕМАНТИЧЕСКОЙ ГРУППЕ ГЛАГОЛОВ ДВИЖЕНИЯ В АЛТАЙСКОМ ЯЗЫКЕ 1
}

\section{ON THE LEXICAL-SEMANTIC GROUP OF VERBS OF MOVEMENT IN THE ALTAI LANGUAGE}

\section{N. Tydykova}

Summary: The article describes the lexical-semantic group of verbs of movement in the Altai language. The main semantic feature of the verbs of movement is the feature "movement". Verbs of movement are divided into 2 classes: verbs of translational movement, denoting directional movement, and verbs of non-translational movement, denoting movement in place or within a very limited, enclosed space.

Keywords: lexical-semantic group, verbs of movement, direction of movement, pace of movement, method of movement.

\author{
Тыдыкова Надежда Николаевна \\ С.н.С., БНУ «НИИ алтаистики им. С.С. Суразакова», \\ г. Горно-Алтайск \\ ntydykova@mail.ru
}

Аннотация: В статье описывается лексико-семантическая группа глаголов движения в алтайском языке. Основным семантическим признаком глаголов движения выступает признак «движение». Глаголы движения делятся на 2 класса: на глаголы поступательного движения, обозначающие направленное движение и на глаголы непоступательного движения, обозначающие движение на месте или в пределах очень ограниченного, замкнутого пространства.

Ключевые слова: лексико-семантическая группа, глаголы движения, направленность движения, темп движения, способ движения.
$\Pi$ онятие «движение» является одним из важнейших элементов, создающих понятийную картину мира. Известно, что без движения нет и жизни. Человек узнаёт окружающий его мир, самого себя и живёт благодаря тому, что есть движение. Движения могут быть различными. И это находит отражение в любом языке. Не случайно данная тема стала объектом исследований и у лингвистов, например, у таких зарубежных и отечественных учёных, как Ш. Балли, П. Робер, В.А. Богородицкий, В.Г. Гак, Э.Р. Тенишев, Д.Г. Тумашева, В.Н. Топоров и др., которые описывают типы движений, связанных так или иначе с человеком или вообще с живым существом. Объектом таких исследований стали глаголы движения.

Под глаголами движения понимаются глаголы, обозначающие видимое физическое перемещение субъекта в пространстве.

Ш. Балли, анализируя смысловые группы лексического состава языка, противопоставлял «движение» понятию «покой» и в рубрику «Виды движения» у него попадали различные глаголы, которые хотя и не показывают перемещения в пространстве, все же обозначают, что субъект не находится в состоянии покоя: saisir 'хватать', casser 'ломать', vibrer 'дрожать', frotter'тереть' и т.д. К числу глаголов, показывающих направление движения, он относит vêtir 'одевать', ouvrir 'открывать', meler 'смешивать' и др. [Балли, 1955, с. 198]. П. Робер в своем словаре приводит список
279 «важнейших глаголов движения», среди которых находятся такие, как palpiter 'трепетать', plier 'сгибать', respirer 'дышать', tordre 'скручивать' и мн. др. [14, с. 57].

Ряд исследователей русских глаголов, начиная с А.А. Шахматова [13] и В.А. Богородицкого [3], отмечают следующие признаки, которыми должны обладать глаголы движения:

а) парная соотнесенность идти / ходить, характерная для всех глаголов движения (перемещения);

б) способность создавать различные типы грамматических конструкций (субъектные и субъектнообъектные: идmu - ходить, нести - носить);

в) способность сочетаться со словами, обозначающими место и направление действия;

г) широкая возможность развития префиксации, передающей указание на направление и характер движения (идти - пойти - пройти - перейти уйтu - выйmu - отойти и т.д.).

Подробное описание глаголов движения дает В.Г. Гак. Он выделяет широкое и узкое понятие движения. Под широким значением автор понимает слова, обозначающие широкие понятия, противопоставленные любому виду покоя; под узким - передвижение, изменение, местонахождение объекта [5].

B.Н. Топоров, описывая глаголы движения русского

1 Исследование выполнено при финансовой поддержке РФФИ и Республики Алтай в рамках научного проекта № 20-412040008 «Лексико-семантические группы алтайских глаголов (идеографическое описание)». 
языка, выделяет глаголы, обозначающие горизонтальное движение линейного характера (идти, ходить, броdumb, шагать, мчаться, гулять, собираться), движение хаотично-колебательного или вращательного характера (вертеться, вращаться, качаться, колебаться) и др. [9, с. 37-38]. При этом отмечается, что центральную позицию занимают глаголы поступательного движения.

В лексико-семантическую группу (далее - ЛСг) глаголов движения включалось различное количество лексических единиц, и их классификация проводилась поразному.

Но в качестве ядерного члена всей сферы выступает глагол двигаться, так как он имеет предельную простоту семантической структуры и является идентификатором в данной группе глаголов движения. Глагол двигаться выражает идею движения, перемещения в пространстве субъекта или объекта в самой общей, абстрактной и нейтральной форме. В этом слове заключен ядерный признак глаголов движения - «линейное перемещение». Все остальные слова уточняют общую идею, общее понятие, расчленяют его с точки зрения направления движения, интенсивности его проявления, способа осуществления.

В качестве ведущих членов группы глаголов перемещения рассматриваются также коррелятивные глаголы идти и ходить. Эти глаголы обладают наибольшим количеством употребительных лексико-семантических вариантов, они обладают развернутой семантической системой, широкой сочетаемостью, они наиболее нейтральны стилистически, коммуникативно, грамматически, просодически и т.п., что ставит их в центр всей группы глаголов движения.

В тюркских языках глаголы движения также занимают особое место. Глаголам движения посвящен труд Н.К. Дмитриева, который отмечал, что глаголы движения в тюркских языках не дифференцируются по способу движения, что, как известно, является основным критерием при классификации русских глаголов движения. По его мнению, все глаголы движения можно разделить на две группы: 1) глаголы, обозначающие направление движения; 2) глаголы, обозначающие способ движения. Существует несколько глаголов, которые занимают как бы промежуточное положение между этими группами [6].

В.Ф. Вещилова называет глаголами движения глаголы, «обозначающие перемещение субъекта в пространстве». Она делит глаголы движения турецкого языка на четыре подгруппы: 1) глаголы способа движения (называют способ без указания направления); 2) глаголы направления, указывающие направление движения; 3) глаголы способа и направления движения; 4) глаголы отвлеченного значения, обозначающие сам процесс движения, не указывающие ни на способ, ни на направление [4, с. 111].
Оригинальную семантическую классификацию тюркских глаголов движения дал Э.Р Тенишев. По семантическим признакам глаголы движения разбиваются им на две группы: 1) глаголы общего значения и 2) глаголы частного движения. Первая группа включает в себя четыре антонимических по значению глагола, а вторая на основе частных признаков распадается на три группы: а) глаголы, указывающие на способ движения; б) глаголы, указывающие на преодоление преграды в движении; в) глаголы, указывающие скорость движения [8, с. 291].

Ю.В. Псянчин в своей работе делит глаголы движения также на две группы: 1) класс глаголов движения по горизонтали с ядерными значениями приходить / уходить (твердая поверхность, жидкая среда, газообразная среда)»; 2) класс глаголов движения по вертикали с ядерными значениями подниматься / спускаться (твердая поверхность, жидкая поверхность и газообразная среда) [7, c. 8-18].

В алтайском языкознании глаголы движения специально не исследовались. Поэтому в данной статье мы попытаемся дать характеристику глаголов движения в алтайском языке.

В алтайском языке, как и в других тюркских языках, органическим признаком глаголов движения, сущностью их своеобразия, является направленность движения, которая четко отражена в смысловой структуре большинства глаголов. Отсутствие в алтайском языке префиксов, как и в других тюркских языках, выполняющих в русском языке функцию выражения различного рода направлений, компенсируется лексическим путем: в содержание глагола наряду с другими смысловыми элементами входит и обозначение направления. Они выражают идею направленности действия имплицитно, самими своими корнями, не нуждаясь для этого ни в каком морфологическом оформлении.

Основным семантическим критерием анализируемых глаголов должно быть наличие идеи пространственного перемещения предмета или лица. Помимо этого, глаголы движения характеризуются обязательной адвербиальной детерминацией направления (тӱрген базар 'ходить быстро', орой келер 'прибывать поздно'). Особо выделяется способность глаголов соотноситься с типовыми вопросами (кайдаар?'куда?' кайдан?'откуда?'), их способностью легко создавать определенные типы грамматических конструкций, обозначающих место / направление движения.

В качестве основного «интегрирующего» семантического признака глаголов движения выступает признак «движение». Семантической доминантой группы признается глагол $j \ddot{p}=$ «ходить, идти, ездить, двигаться», который в общем выражает семантику всей группы. До- 
казательством тому служит: 1) простота семантической структуры - глагол не маркирован семами «среда», «способ», «направленность», «интенсивность»; 2) большие сочетаемостные возможности: а) в роли действующего лица могут выступать люди, животные, транспортные средства, существительные, обозначающие природные явления и т.д. (кижи јӱрген 'человек ходил', айу јӱрген 'медведь ходил', автобус јӱрген 'автобус ходил', булутmар јӱре берт 'облака ушли'); б) возможность сочетаться с различными уточнителями направления (прямо, в сторону, от меня, туда, отсюда - туура јӱре берер 'уйти в сторону', мынан јӱрер 'уходить отсюда'), интенсивности (быстро, медленно - араай јӱрер 'ходить медленно, тихо'), способа (шагом, рысью и т.д. - јойу јӱрер'двигаться пешком'), самостоятельности (јаныскан јӱрген 'двигался один' и атmу јӱрер 'ездить на лошади') и т.д.

Вслед за А.Н. Чугунековой [12] и В.С. Барыс-Хоо [2] глаголы движения в алтайском языке по характеру движения подразделены нами на 2 класса: 1) глаголы поступательного движения, обозначающие направленное движение; 2) глаголы непоступательного движения, которые обозначают движение на месте или в пределах очень ограниченного, замкнутого пространства (ядерные элементы в них отсутствуют).

В данной статье рассматриваются глаголы поступательного движения. Глаголы поступательного движения называются иногда глаголами направленного движения [11]. Они объединены по наличию в их значении общей категориально-лексической семы «передвижение в пространстве», различаются между собой по абстрактной семантической категории «направленность движения», «среда передвижения», «способ передвижения», «трасса передвижения», «темп передвижения», «образная характеристика передвижения».

Идентификатором ЛСГ глаголов поступательного движения выступает глагол јӱр= 'идти, ехать, уезжать', передающий не только общее значение передвижения 'идти, ехать', но и направленное движение 'уходить, уезжать'. Данный глагол нейтрален к семантическим признакам, которые имеются в основе регулярных противопоставлений остальных глаголов движения: по суше / по воде / по воздуху / шагом / ползком и т.д. Субъектом движения могут быть живые существа и неживые предметы или явления. Значение движения глагола јӱр= 'идти, ехать, уезжать' лучше всего передаётся в составе глагольной аналитической конструкции, где глагол јӱр= является первым её компонентом, а вторым компонентом являются вспомогательный глагол бер= 'давать': Койло, билерин бе... менин кайдӧӧн-кайдӧӧн, ыраак-ыраак јӱре берер кйӱним бар... (ЛК, ТКБ, 35) 'Знаешь, Койло..., у меня есть желание уехать куда-нибудь, далеко-далеко...'; ... Шуурган эрикчилдӥ-эрикчилдӱ улып, кобыларды тӧмӧн jӱре берет (ЛК, ТКБ, 70) 'Вьюга, тоскливо-тоскливо завы- вая, уходит вниз по логам'.

Вся ситуация поступательного движения характеризуется следующими координатами: субъект, направление $\rightarrow$ финиш (куда направлено движение) и старт (откуда направлено движение) $\rightarrow$ трасса.

Среди классификационных признаков глаголов движения наиболее важным является признак направленности движения, по которому они подразделились на 2 группы: 1) на глаголы направленного (ориентированного) движения и 2) на глаголы ненаправленного (т.е. с невыраженной ориентацией) движения.

\section{1. Глаголы направленного движения.}

а) в горизонтальной плоскости: бар= 'идти, отправляться', кел= 'приходить, приезжать, прибывать', јуукта= 'приближаться', јет = 'доходить, добираться, достигать'.

б) в вертикальной плоскости: чык= в значении 'подниматься, взбираться, восходить', кӧдӥр= 'поднимать', кӧдӱрӱн= 'подниматься', ӧрӧлӧ= 'подниматься вверх, выше; направляться вверх', кармактан= 'карабкаться', тӱш= в значении 'спускаться; снижаться'.

Для раскрытия своего значения все данные глаголы должны быть вместе с локализатором. Они выражают направленность своего действия:

1. относительно субъекта наблюдения: а) глаголами с семантикой движения к субъекту наблюдения (кел= 'приходить, приезжать', јуукта= 'приближаться' и т.д.: биске кел= 'приезжать к нам', бери кел= 'приходить сюда'); б) с глаголами с семантикой движения от субъекта наблюдения (бар= 'идти, ехать, уходить, уезжать', јӱр= в значении 'уходить' и т.д.: айылдан барар 'уходить из дома', јаныскан барар'идти одному', ыраакјӱре берер'далеко уехать';

2. относительно пространства, имеющего внутренний объём или площадь: а) с глаголами с семантикой движения, обозначающего вхождение в объект или покидания объекта (кир= 'входить', кел='приходить'; чык='выходить', бар= в значении 'идти, отправляться', јӱр= в значении 'уходить, уезжать', кач= 'убегать, сбегать', ыра= 'удаляться; отходить', тескерле= 'двигаться назад, пятиться' и т.д.: орооннон јӱре берер 'уехать из страны'; Вокзалга кuрun барзам, табыш эмес табыш (JК, ӰӰС, 117) 'Когда я зашел в вокзал, [там] шум и гам'; Балдар суудан качып чыккылады (ИС, ТӰКА, 90) 'Дети выбегали из воды'; б) с глаголами с семантикой относительно исходного пункта движения: айлан= 'вращаться, вертеться, кружить(ся) вокруг чего-л.' и т.д.: Ак-Адына минеле, бодоп ло арка-туу айланар (JК, ӰӰС, 117) `Оседлав своего коня, будет про- 
сто так кружить вокруг гор'; в) относительно поверхности земли: тӥш= 'спускаться, опускаться', чык= 'подниматься, взбираться' и т.д.: Чындап ma, јер тоозыны тенгериге чыккан, тенгери тоозыны јерге тӥшкен (ЈК, ӰӰС, 117) 'И вправду, земная пыль поднялась к небу, небесная пыль опустилась на землю'.

3. относительно какой-либо точки в пространстве: а) с глаголами с семантикой достижения конечного пункта или приближения к конечному пункту (јет= 'достигать', јуукта= 'приближаться' и т.д.): Удабас ла машина бурулчыкка једе берер, ол тушта онын кӧзине јурттын отторы кӧрӱнбей барар (ЛК, ТКБ, 131) ‘Совсем скоро машина доберётся до поворота, тогда исчезнут в его глазах деревенские огни'; б) с глаголами движения с общим значением 'убегать' (кач= 'убегать' и т.д.): Ӧртӧк карчагадан качып, ӱӱринен айрылып, башка учты (ИС, ТӰКА, 87) 'Утка, убегая от ястреба, отделившись от стаи, полетела отдельно'; в) с глаголами движения с общим значением 'удаляться' (ыра= 'удаляться' и т.д.): Шуралай анча-мынча ырап алала, токтой тӥжӱп, ойто кайа кӧрди (БУ, ӦлЭДУ, 78) 'Шуралай, несколько удалившись, остановившись, снова посмотрела назад '.

2. Глаголы ненаправленного (неориентированного) движения.

Глаголы ненаправленного движения состоят из следующих подгрупп: глаголы с общим значением и глаголы с дифференцированным значением.

Глаголы движения с общим значением представляют глаголы со значением движения в определённой среде: 1) со значением движения по твёрдой поверхности: а) с помощью ног: бас= 'идти, ступать, ходить'; Каракай ӧлӧн обоолоп јаткан јер јаар басты (ЛК, ТУ, 68) 'Каракай пошёл в сторону места, где стогуют сено'; б) с помощью колёс или копыт (мантат = 'ездить; скакать'): Текелер тилдерин јаланып, кӧстӧрин кылайтып, кайра тескерлеп алала, удура мантажала, јарс эдип сӱзӥжет (ИС, ТӰКА, 87) 'Горные козлы, облизывая языки, глядя исподлобья, попятившись назад, поскакав навстречу друг к другу, с треском бодаются'; в) с общим значением 'ползти, двигаться' (јыл= 'ползти'): Anагаш булутmар тенеринин тӥбиле араайынан јылыжып, тӥндйк јаар баргылап јатты (ИС, ТӰКА, 69) 'Беленькие облака, потихонечку двигаясь по глубине неба, направляются на север'; 2) со значением движения в жидкой среде (эжин='купаться'; jӱс='плавать', чӧн='тонуть'): Баштапкы кӱндерде бис ӱзйги јок ойын-јыргалга кирдис: сууга эжинедис, кажык ойнойдыс, чараандар тудадыс (ИС, ТӰКА, 22) 'В первые дни мы вошли в беспрерывную праздную игру: плаваем в реке, играем в «бабки», ловим хариус'; Кереп оодылып чӧнӧрдӧ, ондо кандый алкы-јӧӧжӧ артканын билип болбозын (ББ, УЈ, 46) 'Когда корабль, разбившись, тонет, [ты] не узнаешь, какое там богатство осталось'; 3) со значением движения по воздуху (уч= 'летать'): ... Јылдыс тенериден ӱзйлеле, јерге эмезе уйуктап турган кырлардын бажына јабыс-јабыс учуп тӱжеле, јоголо берет (ЛК, ТУ, 71) '... Звезда, оторвавшись от неба, падая на землю или на вершины спящих гор, летя низко-низко, исчезает'.

Среди глаголов с дифференцированным значением выделяются лексемы, отражающие особенности движения. Это в основном темп движения и способ движения.

По темпу движения они могут быть медленными, более или менее быстрыми: а) глаголы медленного темпа движения (сӱӱрте = 'тащить', јайкан = 'качаться', толго= 'скручивать' и др.): Карануй кирерде, ол Никанорды бистердин окопторыска сӱӱртеп экелген (ЈК, ӰӰС, 89) 'Когда стемнело, он притащил Никанора в наши окопы'; б) глаголы более или менее быстрого темпа движения (бажыр = 'молиться', тара = 'расчёсывать', ӧр= 'заплетать', сӱр= 'пахать' и др.): Толыкта турган иконага крестенип бажырды (ИС, ТӰКА, 30) 'Крестясь на находящуюся в углу икону, молился'; в) глаголы интенсивного темпа движения: (кап= 'хватать', оот = 'разбивать', јырт= 'рвать', јар= 'рубить', јыгыл= 'падать' и др.): Ондый јерлер бар: улус удур-тедир учурашкан ба, јок по, капшай ла мылтыгын кап-чут кабар... (ББ, УЈ, 28) ‘Есть такие места: не успели люди встретиться лицом к лицу или нет, тотчас же быстро хватают ружья....

По способу движения встречаются глаголы: а) с семантикой преодоления препятствия (aш= 'переваливать', кеч='переходить, переправляться', ӧm= 'проходить; пробиваться, пролезать' и др.): Кажатты ажып келеле, катап ла токтой тӱшти (ЛК, ТУ, 33) 'Перевалив высокий берег, снова остановился'; б) глаголы с общим значением 'расходиться в разные стороны' (тара= 'расходиться', тарка='расходиться', јайрадыл='разваливаться; разрушаться' и др.): Ончолоры отурган јерлеринен табышту тургулап, тарап-таркап турдылар (ЛК, ТУ, 40) 'Все с шумом поднимаясь с насиженных мест, расходились'; Ончозы јайрадылып, бӱткйл телекей бузулып јаткандый... (ББ, УЈ, 16) 'Всё вокруг разваливаясь, кажется, будто весь мир рушится'.

Таким образом, рассмотрев глаголы движения в алтайском языке, можно утверждать, что описание лексико-семантических групп глаголов движения может послужить базой для выявления всего комплекса знаний о семантике глаголов, для идеографического описания глагольной лексики алтайского языка.

\section{Список сокрашений}

БУ, ӦлэУ - Б. Укачин. Ӧлӧргӧ јетире эм де узак. - Гор- 
но-Алтайск: Горно-Алтайское отделение Алтайского книжного издательства, 1978.

ЈК, ӰӰС - Ј. Каинчин. Ӱстибисте - Ӱч-Сӱмер. - ГорноАлтайск: ГУ книжное издательство «Юч-Сюмер - Белуха» Республики Алтай, 2003.

ИС, ТӰКА - И. Сабашкин. Турна ӱни кӧндӱгер алдында. - Горно-Алтайск: ГорноАлтайское отделение Алтайского книжного издательства, 1984.

ЛК, ТКБ - Л. Кокышев. Туулардан келген балдар. Горно-Алтайск: Горно-Алтайское отделение Алтайского книжного издательства, 1958.

ЛК, ТУ - Л. Кокышев. Туулардын уулдары. - Горно-Алтайск: Горно-Алтайское отделение Алтайского книжного издательства, 1966.

\section{ЛИТЕРАТУРА}

1. Балли Ш. Общая лингвистика и вопросы французского языка. - М.: Изд. иностр. лит., 1955. - 358 с.

2. Барыс-Хоо В.С. Лексико-семантическая группа глаголов движения в тувинском языке: автореф. дис. ... канд. филол. наук. Новосибирск, 2006. - 21 с.

3. Богородицкий В.А. Общий курс русской грамматики. - 5-е изд. - М.-Л., 1935. - 356 с.

4. Вещилова В.Ф. Глаголы движения в турецком языке // Исследования по сравнительной грамматике тюркских языков. Часть 4. Лексика. - М.: Наука, 1962. - C. 101-115.

5. Гак В.Г. Сопоставительная лексикология: (На материале французского и русского языков). М.: Международные отношения, 1977. - 250 с.

6. Дмитриев Н.К. Глаголы движения. Строй тюркских языков. - М.: Изд-во вост. лит-ры, 1962. - 132 с.

7. Псянчин Ю.В. Лексико-семантическое поле глаголов движения башкирского языка: автореф. дис. ... канд. филол. наук. - Баку, 1990. - 21 с.

8. Тенишев Э.Р. Глаголы движения тюркских языках // Историческое развитие лексики тюркских языков. - М.: Изд-во АН СССР, 1961. - С. 232-294.

9. Топоров В.Н. 06 одном парадоксе движения. Несколько замечаний о сверх-эмпирическом смысле глагола «стоять», преимущественно в специализированных текстах // Концепт движения в языке и культуре. М., 1996. - С. 8-101.

10. Тумашева Д.Г. Семантика аналитических конструкций с глаголами движения // Татарский язык: Лексическая и грамматическая семантика. - Казань, 1984.

11. Усманова М.Г. Функционально-семантическая классификация глаголов башкирского языка. - Уфа: РИЦ БашГУ, 2002. - 212 с.

12. Чугунекова, А.Н. Глаголы движения и формируемые ими модели простого предложения: На материале хакасского языка: автореф. дисс. ... канд. филол. наук: 10.02.02. - Новосибирск, 1998. - 155 с.

13. Шахматов А.А. Синтаксис русского языка. - Л.: Учпедгиз, 1941 - 620 с.

14. Robert P. Dictionnaire alphabétique et analogique de la langue française. V. 4. "Mouvement".

(с Тыдыкова Надежда Николаевна (ntydykova@mail.ru). 